\title{
Impact of Plaque Morphology and Composition on the Mechanisms of Lumen Enlargement Using Intracoronary Ultrasound and Quantifative Angiography After Balloon Angioplasty
}

\author{
Jose Baptista, MD, PhD, Carlo di Mario, MD, PhD, Yukio Ozaki, MD, \\ Javier Escaned, MD, PhD, Robert Gil, MD, Pim de Feyter, MD, PhD, \\ Jos R.T.C. Roelandt, MD, PhD, and Patrick W. Serruys, MD, PhD
}

Limited information is provided by angiography on plaque morphology and composition before balloon angioplasty. Identification of plaques associated with reduced lumen gain or a high complication rate may provide the rationale for using alternative revascularization devices. We studied 60 patients with quantitative angiography and intracoronary ultrasound (ICUS) before and after balloon dilation. Angiography was used to measure transient wall stretch and elastic recoil. ICUS was used to investigate the mechanisms of lumen enlargement among different plaque compositions and in the presence of a disease-free wall (minimal thickness $\leq 0.6 \mathrm{~mm}$ ). Compared with ultrasound, angiography underestimated the presence of vessel calcification ( $13 \%$ vs $78 \%$ ), lumen eccentricity $(35 \%$ vs $62 \%)$, and wall dissection ( $32 \%$ vs $57 \%$ ). ICUS measurements showed that balloon angioplasty increased lumen area from $1.82 \pm 0.51$ to $4.81 \pm 1.43 \mathrm{~mm}^{2}$. Lumen enlargement was the result of the combined effect of an in-

ontrast angiography, the gold standard for the evaluation of coronary artery disease, provides limited information regarding plaque dimensions and composition. ${ }^{1.2}$ Therefore, the impact of plaque morphology and composition, in vivo, on the outcome of balloon angioplasty remains to be fully elucidated. Likewise, restenosis occurring after balloon dilation cannot be accurately predicted by angiography.

Balloon angioplasty is a nondirectional technique; during balloon inflation, factors, such as differences in plaque thickness and composition, may cause an unequal transmission of the balloon circumferential stress to the vessel wall, resulting in different responses of the vessel wall to balloon dilation. Identification of particular plaque types associated with a suboptimal result may provide the rationale for use of alternative devices for a particular lesion. Intracoronary ultrasound (TCUS) provides a unique opportunity not only to identify different

\footnotetext{
From tho Intracoronary Imaging ana Catheterisarion Lasoratorios Tho roxcenter, Erasrrus !niversity. Rotterdarn, The Netherlonds. Dr. Barr tista 's the recipient of a grar: from the Fortugueso Socieriy of Cardiology, Lisbon. Porlugal. Manuscript rece.ved May 12, 1995. rovisoa man sseript received and accepted Septembor 26, 1995.

Audress for raprints: Patrick W. Serruys. MD, PhD Irilracoronary Imaging and Catheterisction Laboratories. Thoraxcenter. Ercsmus Universily Rotterdam. Poslious 17383000 CR Rotterdam. The Neiherlands.
}

crease in the total cross-sectional area of the vessel (wall stretching, $43 \%$ ) and of a reduction in the area occupied by the plaque (plaque compression or redistribution, 57\%). Vessels with a disease-free wall had smaller lumen gain than other types of vessels $12.13 \pm$ 1.26 vs $3.59 \pm 1.51 \mathrm{~mm}^{2}$, respectively, $p<0.01$ ). Wall stretching was the most important mechanism of lumen enlargement in vessels with a disease-free wall $179 \%$ vs $37 \%$ in the other vessels). Angiography revealed a direct correlation between temporary stretch and elastic recoil that was responsible for $26 \%$ of the loss of the potential lumen gain. Thus, lumen enlargement after balloon angioplasty is the combined result of wall stretch and plaque compression or redistribution. ICUS indicates that vessels with a remnant arc of diseasefree wall are dilated mainly by wall stretching compared with other types of vessels and are associated with a smaller lumen gain.

(Am J Cardiol 1996;77:115-121)

plaque compositions, ${ }^{3.4}$ but also to identify different mechanisms of lumen enlargement during balloon angioplasty. ${ }^{2}$ This study evaluates the influence of plaque morphology and composition on the mechanisms of lumen enlargement after balloon angioplasty using quantitative angiography and ICUS.

\section{METHODS}

Patient group: Sixty consccutive patients undergoing balloon angioplasty were studied with ICUS before and after intervention. Thirty-four patients presented with unstable angina (class IIB and IIIB, and IIC and IIIC under the Braunwald classification), ${ }^{5}$ and 26 presented with stable angina pectoris. The investigations were approved by the institutional board of the cardiology department of the Dijkzigi Zickenhuis, and all patients were studicd only after giving informed consent.

Quantitative coronary angiography: All $35 \mathrm{~mm}$ films were analyzed using the Cardiovascular Angiography Analysis System II (CAAS II, Pie Medical, Maastricht, The Netherlands). The automatcd cdge detection of this system has been validated and described in detail elsewhere. ${ }^{6}$

Lesion symmetry (Figure 1) was detined as the coefficient of the left-hand and right-hand distances between the reconstructed interpolated reference diameter and actual vessel contours at the sitc of obstruction. In this 
equation, the largest distance between the actual and reconstructed contours becomes the denominator, so that a perfectly symmetric lesion has a value of 1 and a severely eccentric lesion has a value of $0 .^{7} \mathrm{~A}$ lesion was classified as eccentric when the eccentricity index was $\leq 0.5$.

Dissections, wall stretch, and elastic recoil with angiography: Dissections were evaluated according to the modificd classification of the Heart, Lung, and Blood Institutes. ${ }^{7}$ A dissection was classified as type $A$ in the presence of a small radiolucent area within the lumen of the vessel and as type $\mathrm{B}$ or $\mathrm{C}$ when there was an extravasion of nonpersisting or persisting contrast medium, respectively. A dissection was classified as type $\mathrm{D}$ in the presence of a. spiral-shaped filling defect with delayed distal flow, and as type $\mathrm{E}$ if a persistent lumen defect with delayed anterograde flow was seen on the final angiogram. A filling defect accompanied by a total coronary occlusion was classified as type $F$ dissection.

Temporary wall stretch ${ }^{8}$ was defined as the difference between the mean balloon diameter (of the largest and last balloon used) and minimal lumen diameter after balloon dilation, normalized for vessel size (Figure 2). ElasLic recoil ${ }^{8}$ was defined as the difference between minimal balloon diameter and the minimal lumen diameter after coronary angioplasty normalized for vessel size. This was measured 5 minutes after the last balloon inflation.

Ultrosound study: Before and after coronary interventions, a 4.3Fr mechanical $30 \mathrm{MHz}$ intravascular ultrasound catheter (INSIGHT "3" ultrasound system, CVIS, Sunnyvale, California) was introduced along a 0.014-inch high-torque floppy guidewire. The catheter was advanced distal to the stenosis and a slow manual pullback or (last 22 patients) motorized mechanical pullback at $1 \mathrm{~mm} / \mathrm{s}$

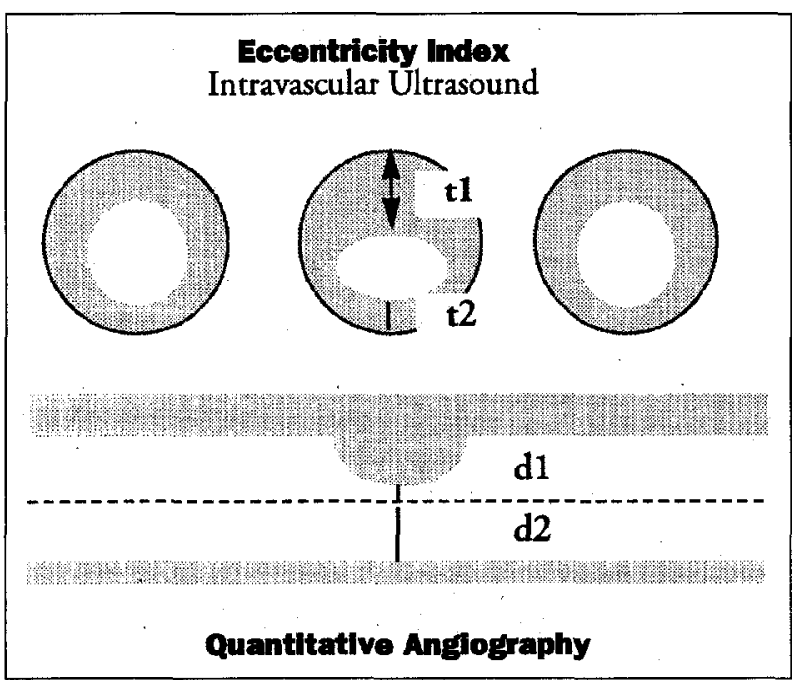

FIGURE 1. Eccentricity index calculated with quantitative angiography and intravascular ultrasound. Intravascular ultrasound allows the direct assessment of the wall thickness so that the eccentricity index is based on the ratio between plaque thickness and the thickness of the opposite wall. Quantitative angiography estimates the eccentricity of a plaque from the distance between the center of the lumen and the luminal contours at the site of the stenosis. In this example, however, the presence of a different thickness of the wall also in the angiographically normal segment induces an underestimation of the plaque eccentricity. CSA = cross-sectional orea. was performed from the distal area to the proximal area to the lesion. The segment comprising the stenotic lesion was examined along the entire length using side branches as landmarks, and the images were recorded on SVHS videotape. The measurement system was digitally calibrated, and after review of each videotape, 1 image at the site of the minimal luminal cross-sectional area before and after intervention was selected for quantitative analysis. Landmarks such as side branches or a particular location of calcium were used to assure the same site of analysis after intervention.

The integrated information acquired during the pullback maneuver along the stenotic segment was used to classify plaque composition according to their ultrasonic appearance ${ }^{3,9}$ as follows:

PLAQUFS WITH LOW FCHOGENICITY ("SOFT PLAQLES") $=>75 \%$ of the plaque area is composed of tissue with an echo density lcss than the reference adventitia.

PLAQLES WITH HIGH FCHOGENICITY ("HARD PLAQUES") $=>75 \%$ of the plaque area is composed of bright echoes, as bright or brighter than the reference adventitia, but without acoustic shadowing.

DIFTLSE: CALCIFIC PLAQUES = bright echoes within a plaque with acoustic shadowing and occupying $>180^{\circ}$ of vessel wall circumference.

PLAQUES WITH A MIXED ECHOGENICITY = when a combination of different types of plaque composition occurs.

Additionally, vessel dimensions were measured as follows ${ }^{9}$ : Lumen area was defined as the integrated area central to the leading edge of the intimal echo. The external elastic membrane area was defined as the integrated area central to media-adventitia interface. The plaque plus media area was defined as the difference between external elastic membrane area and luminal area. From

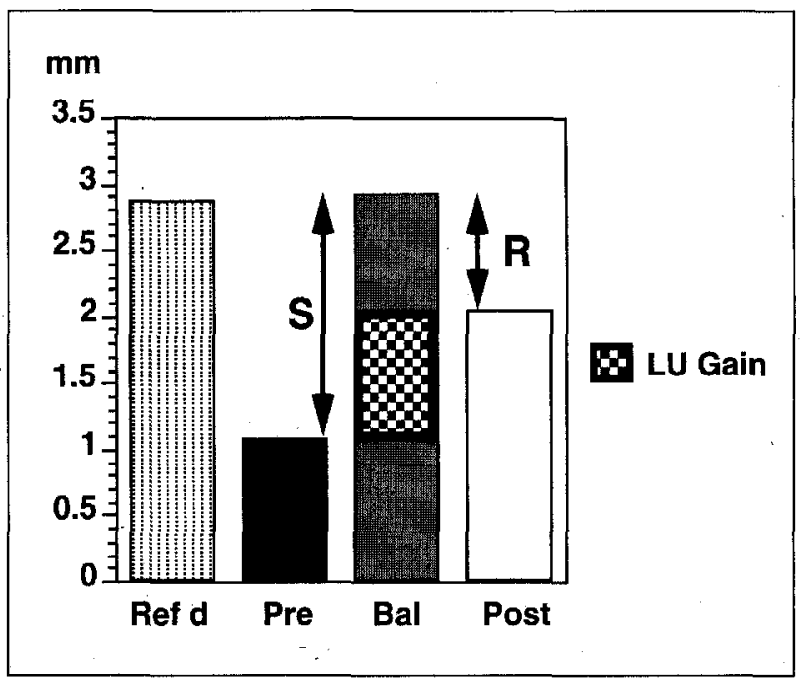

FIGURE 2. Changes in lumen dimensions during bolloon (Bal) dilation. During balloon inflation there was a change in lumen dimensions from $1.08 \mathrm{~mm}$ before (Pre) dilation to $2.93 \mathrm{~mm}$ during maximal balloon pressure (i.e., representative of the Iransient wall streich [S]]. After balloon deflation, there was a decrease in the lumen dimension, from the theoretically maximal lumen dimension toward the final lumen size (Post). This loss in lumen size is the result of elastic recoil (R). The difference between transient wall stretch and elostic recoil is the octual lumen gain (LU Gain). Reference diameter (Ref d) is also shown for comporison. 
comparison of these measurements at the site of the minimal luminal cross-sectional area before and after angioplasty, several indexes were calculated including: (1) wall stretch or acute vessel, which is the dilation difference in external elastic membrane area before and after intervention. This differs from transient wall stretch measured with angiography, because this is the "permanent" plastic wall deformation occurring after the deflation of the angioplasty balloon; and (2) plaque reduction, which is the difference in plaque plus media area before and after intervention. In the presence of calcific plaques, the contour of the external elastic membrane was drawn assuming a circular vessel shape in the shadowed segment or drawing the contour of the continuous vessel segment without calcium. ICUS eccentricity index was obtained dividing the minimal by the maximal plaque thickness. A plaque was considered eccentric when the eccentricity index calculated as the minor diameter divided by the major diameter was $\leq 0.5$. A vessel was classified as having a disease-free wall when the plaque minimal thickness was $\leq 0.6 \mathrm{~mm}$, irrespective of its eccentricity (Figure 3).

Variability of the intravascular ultrasound-determined lumen dimensions: Values of the variability of ICUS dimensions have been previously published by our group. ${ }^{10,11}$.

TEARS AND DISSECTIONS: Tears or fractures were defined as a demarcated, focal, superficial break in the linear continuity of the plaque that extended only in a radial direction. ${ }^{12}$ Dissections were defined as demarcated ruptures of the plaque with circumferential or longitudinal involvement of the internal elastic membrane. ${ }^{12}$

Procedure technique: During the procedures all patients received aspirin $(250 \mathrm{mg})$ and intracoronary isorsobide dinitrate ( 1 to $3 \mathrm{mg}$ ) before and after the procedure, and underwent total anticoagulation with heparin, so that the activated clotting time was $>300$ seconds. Selective coronary arteriography was performed in multiple matched views before and after the coronary interventions. After the passage of a 0.014-inch guidewire across the target lesion, ICUS was performed with the guidance of a fluoroscopic window and multiple contrast injections. This assured proper comparison between ultrasound and angiographic images. Coronary angioplasty was performed according to standard practice.
Statistical analysis: All continuous variables are expressed as mean \pm SD. The Student's $t$ test was used for analysis of continuous data. The chi-square test and Fisher's exact test were used to compare differences between proportions. Agrccment between the 2 techniques was determined using the Cohen Kappa coefficient. A p value $<0.05$ was considered statistically significant.

\section{RESULTS}

Patient and target lesion characteristics prior to balloon dilation are shown in Table I. Fluoroscopy underestimated the presence of calcium at the target lesion compared with ultrasound ( 8 patients [13\%] vs 47 patients [78\%], respectively, $\mathrm{p}<0.0001)$. An eccentric plaque was more often judged to be eccentric with ultrasound (37 patients, 62\%) than with angiography (21 patients, 35\%, $\mathrm{p}=\mathrm{NS}$ ) (Table II). Patients presenting with unstable coronary syndromes had a plaque composition similar to patients with stable angina.

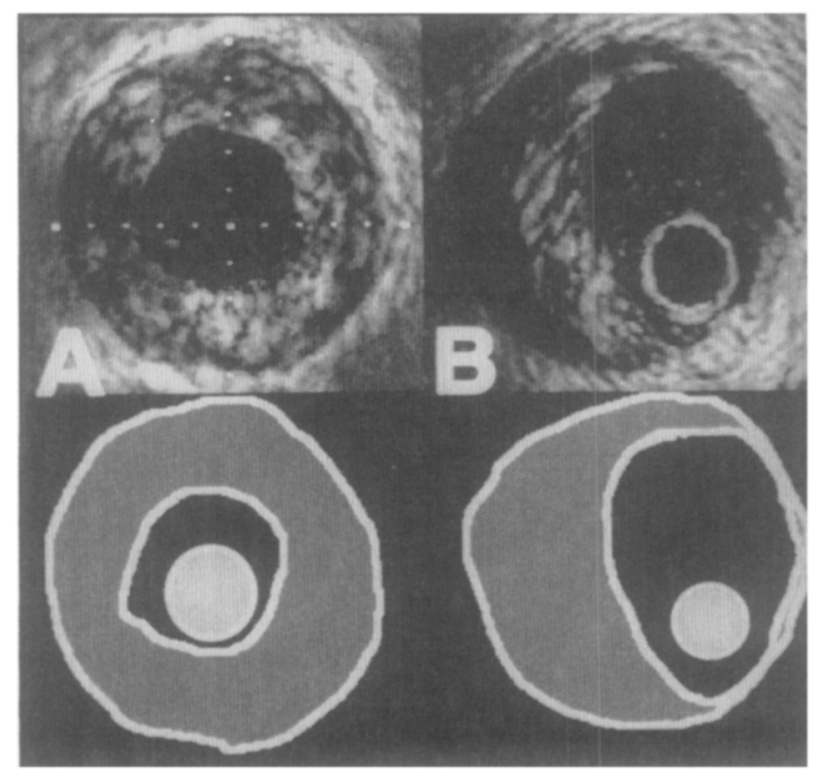

FIGURE 3. A, an example of a very concentric plaque. $B$, an example of a very eccentric plaque with a remnant arc of disease-free wall.
FIGURE 4. Left panel, changes in lumen area (LA-A), plaque plus media area $(P+M-A)$, and external elastic membrane area (EEM-A) with balloon angioplasty. Right panel, relative change in plaque reduction $(\Delta P+M-A)$ and wall stretch ( $\triangle$ EEM-A) for the final lumen.

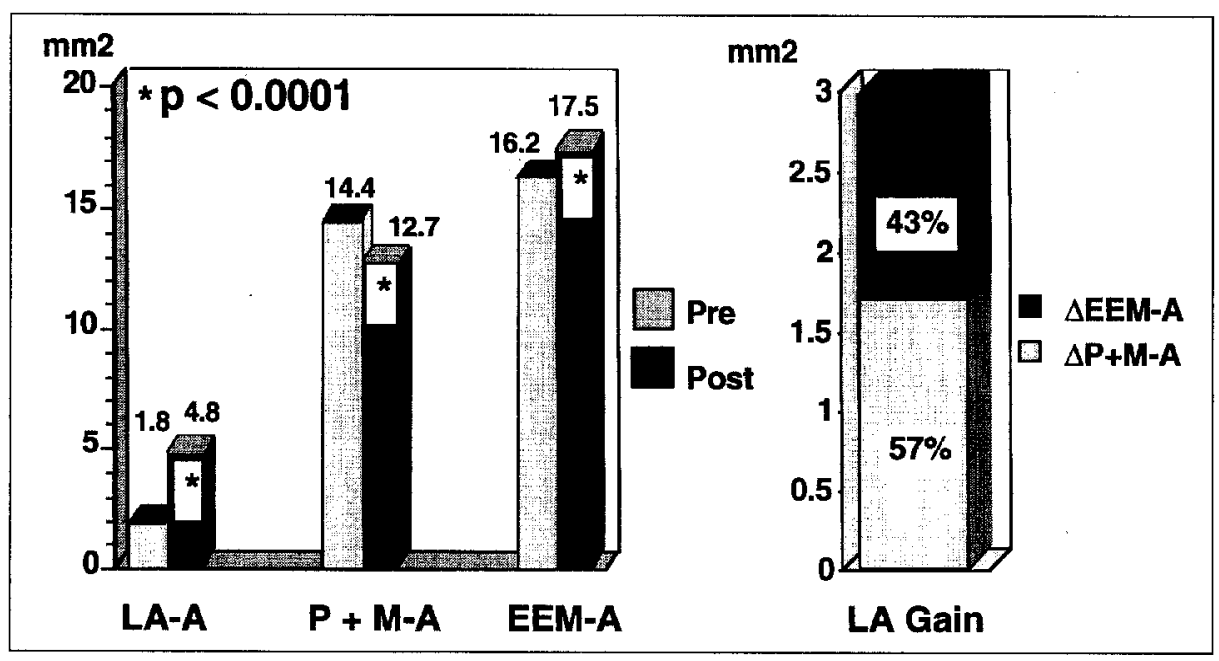


TABLE I Patient and Target Lesion Characteristics Before Balloon Dilation $(n=60)$

\begin{tabular}{|lc|}
\hline Demographics & No. $(\%)$ \\
\hline Age (mean \pm SD) & $58 \pm 9$ years \\
Sex & $50(83)$ \\
Men & $10(17)$ \\
Women & \\
Angina type & $26(43)$ \\
Stable & $34(57)$ \\
Unstable & \\
Coronary artery & $27(45)$ \\
Left anterior descending & $14(23)$ \\
Left circumflex & $19(32)$ \\
Right coronary artery & $26(43)$ \\
KUS characteristics & $1(2)$ \\
Soft plaques & $4(7)$ \\
Hard plaques & $29(48)$ \\
Diffuse calcific & $13(22)$ \\
Mixed plaques & $47(78)$ \\
No calcium & \\
Calcium & \\
\hline ICUS = infracoronary ultrasound. & \\
\hline
\end{tabular}

Angiographic measurements: The minimal lumen diameter increased significantly after balloon angioplasty, from $1.08 \pm 0.43$ to $2.04 \pm 0.48 \mathrm{~mm}(\mathrm{p}<0.0001$ ) (Table III). Balloon artery ratio using the measured mean balloon diameter balloon was $1.12 \pm 0.25$. Temporary wall stretch during balloon inflation was $0.65 \pm 0.25$ of the reference vessel size. After balloon dilation, $0.26 \pm 0.17$ of the target reference size was lost due to elastic recoil.
TABLE II Concordance Between Intracoronary Ultrasound and Contrast Angiography for Determination of Lesion Eccentricity in 60 Patients

\begin{tabular}{|lccc|}
\hline & Angio. Concentric & Angio. Eccentric & Total \\
\hline ICUS concentric & 17 & 6 & 23 \\
ICUS eccentric & 22 & 15 & 37 \\
Total & 39 & 27 & 60 \\
\hline \multicolumn{4}{|l}{ Angio. = contrast angiography; ICUS = intracoronary ultrasound. } \\
\hline
\end{tabular}

Temporary wall stretch and elastic recoil were not significantly influenced by the determined angiographic eccentricity. Temporary wall stretch was directly correlated with relative elastic recoil $\left(Y=0.275 \mathrm{x}+0.071, \mathrm{r}^{2}\right.$ $=0.168, p<0.005$ ).

Ulirasound measurements: After balloon dilation there was a significant increase in lumen area, from $1.82 \pm$ 0.51 to $4.81 \pm 1.43 \mathrm{~mm}^{2}$ (p <0.0001) (Table IV). This was achieved by a combination of plaque reduction (1.72 $\pm 1.86 \mathrm{~mm}^{2}, 57 \%$ of lumen gain) and wall stretch $(1.27$ $\pm 1.84 \mathrm{~mm}^{2}, 43 \%$ of lumen gain) (Figure 4). Plaque composition did not seem to influence the magnitude of lumen gain after balloon dilation $\left(2.62 \pm 1.43 \mathrm{~mm}^{2}\right.$ for soft plaques vs $3.29 \pm 1.66 \mathrm{~mm}^{2}$ for other types of plaques, $p=$ NS). The presence of an area of diseasefree wall was associated with lower lumen gain after intervention $\left(2.13 \pm 1.26 \mathrm{~mm}^{2}\right.$ for disease-free wall vs $3.59 \pm 1.51 \mathrm{~mm}^{2}$ for no disease-free wall, $\mathrm{p}<0.001$ ) Also, lumen enlargement after balloon angioplasty was obtained by different mechanisms according to the pres-
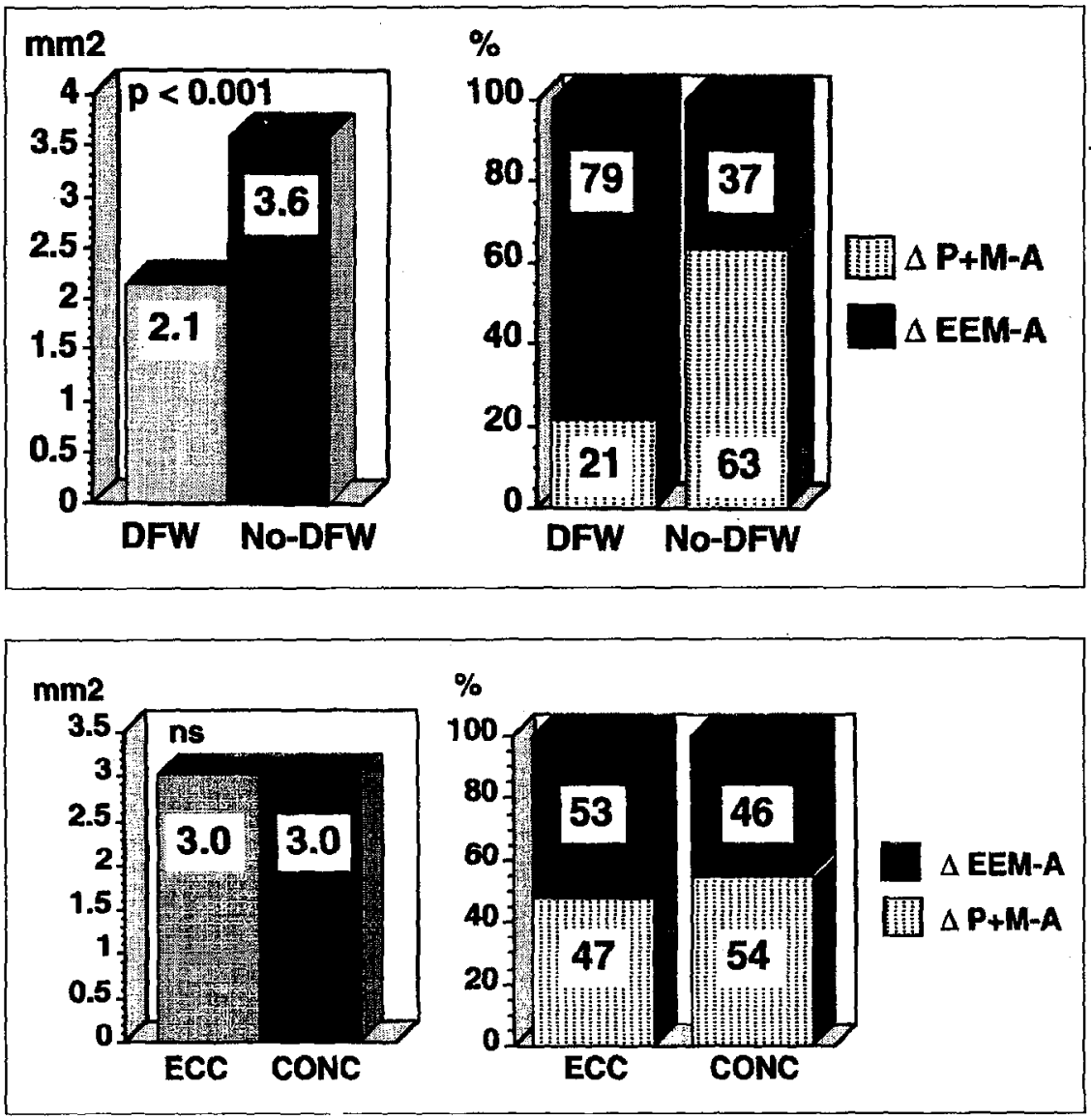

FIGURE 5. Left panel, comparison of the lumen gain by ultrasound after balloon angioplasty in patients with a lesion with a remnant arc of disease-free wall (DFW) and in patients without a disease-free wall (NoDFW. Right panel, relative change in plaque reduction $(\triangle P+M-A)$ and wall stretch $(\triangle E E M-A)$ for the final lumen gain in these 2 groups of patients.

FIGURE 6. Left panel, comparison of the lumen gain by uiltrasound after balloon angioplasty in patients with an eccentric plaque (ECC) and in patients with concentric plaques (CONC). Right panel, relative change in plaque reduction $(\Delta \mathrm{P}+\mathrm{M}$ $A)$ and wall stretch $(\triangle E E M-A)$ for the final lumen gain in these 2 groups of patients. 
ence or absence of a disease-free wall (Figure 5). In patients with a diseasefree wall, lumen enlargement was achieved mainly by wall stretch (1.68 $\pm 1.45 \mathrm{~mm}^{2}, 79 \%$ of lumen gain) and, additionally, by plaque compression or redistribution $\left(0.45 \pm 1.35 \mathrm{~mm}^{2}, 21 \%\right.$ of lumen gain). This contrasted with the mechanisms of lumen enlargement when there was no preserved arc of normal wall (wall stretch $1.33 \pm 1.85$, $37 \%$ of lumen gain, plaque compression, or redistribution, and $2.26 \pm 2.02$, $63 \%$ of lumen gain). These differences in the mechanisms and magnitude of balloon dilation were due to the presence of an area of disease-free segment and not the result of plaque eccentricity (Figure 6), since eccentric plaques with or without a disease-free wall had a similar lumen gain after balloon angioplasty when compared with concentric plaques $\left(3.00 \pm 1.70 \mathrm{~mm}^{2}\right.$ for eccentric plaques vs $2.95 \pm 1.34 \mathrm{~mm}^{2}$ for concentric plaques, $p=N S$ ) and comparable mechanisms of lumen enlargement (wall stretch $1.59 \pm 1.75 \mathrm{~mm}^{2}, 53 \%$ of the lumen gain for eccentric plaques vs wall stretch $1.36 \pm$ $1.72 \mathrm{~mm}^{2}, 46 \%$ of lumen gain for concentric plaques).

Lumen morphology after balloon dilation: ICUS detected dissections more frequently than angiography (34 patients [57\%] vs 19 patients [32\%], respectively, $\mathrm{p}=$ $0.01)$. Additionally, an irregular lumen contour was identified in 21 more patients (35\%) with ICUS. The degree of agreement between the 2 techniques for the detection of dissections was low (kappa 0.27) (Table V). Figure 7 is an example of dissection starting at the transition of the normal wall with the atheroma. The dissection rate after balloon dilation was not associated with plaque composition ( 12 of 26 [46\%] for soft plaques vs 22 of $34[65 \%]$ for other types of plaques, $p=N S$ ) or with the presence of calcium in the target lesion (28 of 47 [60\%] for calcific plaques vs 7 of 13 [54\%] for no calcium, $p$ = NS). Likewise, ICUS-determined plaque eccentricity was not associated with a higher likelihood of developing dissection after balloon dilation (24 of $37[65 \%]$ for eccentric plaques vs 10 of 23 [45\%] for concentric plaques, $\mathrm{p}=\mathrm{NS}$ ). A nonsignificant larger lumen gain was associated with the presence of wall dissections detected with ICUS after balloon dilation (3.23 \pm 1.70 $\mathrm{mm}^{2}$ for dissection vs $2.71 \pm 1.40 \mathrm{~mm}^{2}$ for no dissection, $\mathrm{p}=\mathrm{NS}$ ).

\section{DISCUSSION}

Until recently, the mechanisms of lumen enlargement after balloon angioplasty were mainly derived from necropsy, animal models, or in vitro studies. ${ }^{13-15}$ Extrapolation of these data to a clinical setting may be mislcading because several biases may occur. For instance, patients dying after balloon angioplasty may have a higher rate of extensive dissections than survivors. Animal
TABLE V Concordance Between Intracoronary Ulitrasound and Contrast Angiography for the Detection of Wall Dissections in 60 Patients

\begin{tabular}{|lccc|}
\hline & Angio. Smooth & Angio. Dissection & Total \\
\hline ICUS smooth lumen & 22 & 4 & 26 \\
ICUS wall dissection & 19 & 15 & 34 \\
Total & 41 & 19 & 60 \\
\hline
\end{tabular}

Angio. dissection = dissection class type B or higher; ICUS wall dissection $=$ tear or dissection by intracoronary ultrasound.

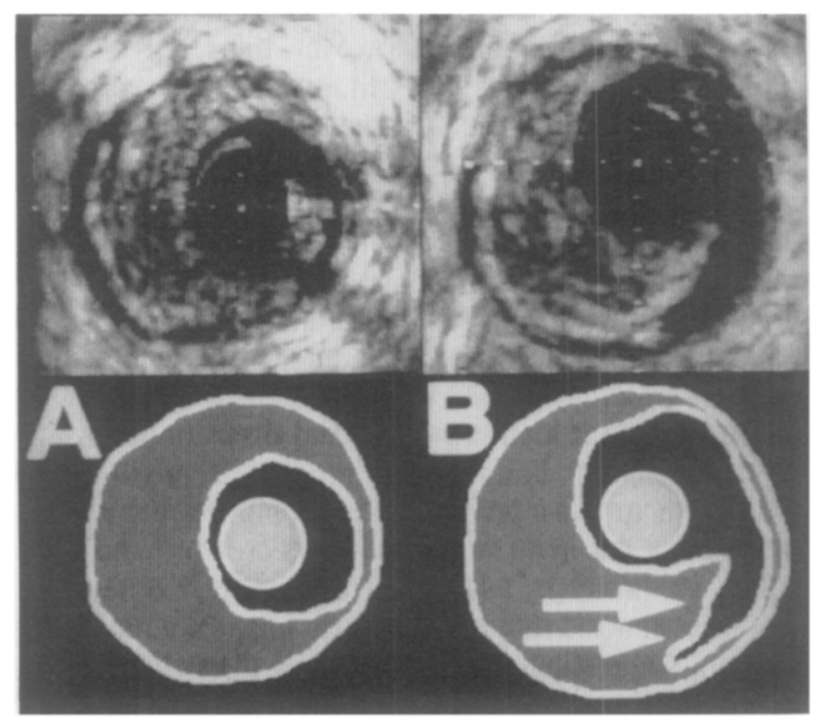

FIGURE 7. (A), an eccentric lesion with a disease-free wall before balloon angioplasty; (B), after balloon dilation there was a wall dissection occurring at the transition of the normal wall with atheroma. 
studies of induced atherosclerosis have a preponderance of soft young plaques. different from the more heterogeneous plaque composition found in in vivo patients; therefore, different mechanisms of lumen enlargement may operate. ${ }^{16}$

Despite the high success rate of balloon angioplasty, the same treatment (balloon inflation) is applied to most plaques, irrespective of their histologic composition and morphology. It is appealing to think that new devices may have a higher impact if used on plaque types associated with a lower success rate or high complication rate after balloon dilation.

We lound that there are important discrepancies between ICUS and angiography for the correct identification of plaque calcification, plaque eccentricity, and residual plaque burden. All these parameters were underevaluated by angiography, and our results are in agreement with others. ${ }^{17}$ Undetected vessel calcification and eccentricity may have an impact on the outcome of some revascularization techniques, such as laser and atherectomy. ${ }^{17,18}$ Therefore, ICUS guidance may be of considerable help in the selection of the most appropriate revascularization device. Importantly, the angiographic unsuspected residual plaque burden ${ }^{19}$ may bear important impact on the renarrowing process. ${ }^{20} \mathrm{~A}$ recent interim analysis of the Guidance by Ultrasound Imaging for Decision Endpoints trial ${ }^{20}$ identified residual plaque burden by ultrasound as one of the most important predictive factors for restenosis among several angiographic and ultrasound parameters.

Comparison with previous studies: Although the first described mechanism of lumen enlargement was plaque compression, ${ }^{16}$ necropsy studies identilied plaque dissection as the most significant mechanism. ${ }^{16.21}$ Only recently, ICUS was used to elucidate the mechanisms of lumen enlargement after balloon dilation in vivo. ${ }^{22-25} \mathrm{In}$ peripheral arteries, dissections were reported in a high percentage of patients and were selected as the most important mechanism of vessel enlargement secondary to neolumen formation. ${ }^{22}$ However, the relative contribution of this mechanism is more diflicult to assess in coronaries arteries, because the relatively bulky ultrasound catheters can "tack-up" dissections against the vessel wall, rendering the detection of dissections more elusive. In our study, ultrasound clearly identified wall dissection in $57 \%$ of patients, and an irregular lumen contour compatible with small intimal tears in $>35 \%$ of patients. Therefore, the true incidence of plaque fractures is underevaluated even with ICUS, as shown by angioscopy that identifies laps and dissections in $94 \%$ of patients after balloon dilation. ${ }^{25}$ It is possible that plaque fracture is a prerequisite to achieve acute wall dilation, as it has been suggested by necropsy ${ }^{16}$ and ultrasound studies. ${ }^{26}$ In addition, Honye et al ${ }^{26}$ observed a higher restenosis rate in concentric plaques without dissection, suggesting that limited wall dissection can be beneficial for a long-term lumen patency. In our study, wall stretch and plaque compression or redistribution contributed in similar proportions to the final lumen dimensions after angioplasty (43\% vs $57 \%$, respectively). Our results are a compromise between those report- ed by Braden et al, ${ }^{24}$ who identified wall stretch as the major factor responsible ( $81 \%$ of the lumen gain) for lumen gain, or those of Suneja et al, ${ }^{23}$ who reported plaque reduction as major mechanism of angioplasty (94\% of the lumen gain). These discrepancies in the mechanisms of balloon dilation may be in part the result of different plaque morphologies. Although wall stretch is an important mechanism of lumen enlargement, angiography identified that $26 \%$ of the potential lumen gain was immediatcly lost after balloon dellation as a result of the elastic recoil. The only variable related to the magnitude of the elastic recoil was temporary stretch, as already described by others. ${ }^{27}$ The poor correlation between angiographic and ultrasound lumen dimensions after angioplasty ${ }^{2}$ may explain the lack of corrclation between plaque composition or morphology and the magnitude of the elastic recoil.

Influence of plaque composition and thickness on the results of balloon dilation: Necropsy studies have indicated that eccentric plaques with a disease-free wall are mainly dilated by localized wall stretching. ${ }^{16}$ Our study confirms in vivo that the presence of an area of relatively disease-free wall has considerable impact on the mechanisms of lumen enlargement after balloon angioplasty. Stenotic lesions with a disease-free wall werc associated with lower lumen gains after balloon dilation $(2.13 \pm$ $1.26 \mathrm{~mm}^{2}$ for disease-(ree wall vs $3.59 \pm 1.51 \mathrm{~mm}^{2}$ for diseased wall, $p<0.001$ ), and this lumen enlargement was mainly obtained by wall stretch ( $79 \%$ of lumen gain) as opposed to plaques without a disease-free wall (37\% of lumen gain). Moreover, this phenomenon was specifically related to the presence of a disease-free wall, because eccentric plaques as opposed to concentric plaques did not respond in a different manner after balloon angioplasty. Thesc findings are supported by other studies that demonstrate that lesions with a disease-free wall may be more prone to vasospastic phenomena and higher elastic recoil becaluse they have a preserved segment of media. ${ }^{16}$ However, recoil is most likely the explanation for the lower lumen gain obtained by these plaques, since intracoronary isorsobide dinitrate was given routinely before each ultrasound examination to relieve any abnormal vasomotor tone. These data arc in disagreement with necropsy data showing larger lumen gains observed in eccentric plaques after angioplasty. ${ }^{21}$ In postmortem analysis, balloon dilation has taken place before morphometric analysis, so that plaque remodeling and redistribution induced by the barotrauma may have interfered and thereby invalidated the conclusions of these necropsy studies. In our study, plaque thickness and the eccentricity index were measured before balloon dilation.

Dissections after angioplasty generally occur at areas of local high shear stress, ${ }^{28}$ at transitions between normal wall and atheroma ${ }^{29}$ or near deposits of calcium. ${ }^{30}$ Our data did not clearly identify a particular plaque type with a higher likelihood of developing dissection. However, in most of the patients, calcium was present in $<25 \%$ of the vessel circumference, and the true incidence of plaque fractures is underestimated by ICUS in the coronary arteries. ${ }^{25}$ 
1. Dı Mario C, Lscaned J, Bapusta J. I laase .I, O/aki Y. Roelandt JR TC, Serruys PU. Advantages of intracoronary ultrasound for the assessment of viscular dimensious: a comparison will quantitative angiograph. J Intenen Cardiol 1994:7:1-14. 2. Baptista .l. di Mario C. Liscaned .l. Nmese M. Oraki Y, de Fevicr P. Rocland JRTC. Sennys PW. Intracoronary two-dimensional ultrusound imaging in the assessincent of plaque morphology and planning of coronary interientions. Am Heart J 1995: 129:1/17-181.

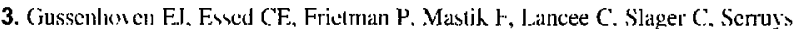
PW. Gerritsen P. P'ieterman H. Bom N. Intravascular eclocardiographic anscssment of sescel uall characteristics, a correlation with bjalology, Int J Card hraging 1989: $4: 105-116$.

4. Di Mario C. The SHK. Madrestma S. van Suylen RJ. Wilson RA. Bom N. Surruys PW: Gissenhowen HJ. Roelandi JR'TC: Delection and characterization of vascular lesions by intravascular ultrasound: an in vitro sluds correlated with histology. J Am Sor Echocardiogr 1992;5:135-146.

5. Brumnald L. Linstable angma: a classification. Circulation 1989:80:410-114 6. Ilaase J. Di Mario C. Slager (J. van der Gissen. den Boer A. de Fey ler PJ. Rejber JHIC. Verdouw PD. Serruys PW. In-vivo validation of on-line and of J-line geometric coronary measurements using insertion of stenosis phantoms in porcine coronary arterics. Cath Cardiowasc Diagn 1992;27:16-27.

7.F.Cermans WRA. Rensing BJ. I'oley DP. Deckers JD. Rutsch W. Funanuclsson H. Danchin N. Wijns W'. Chappuis I:, Serruys PW'. Therapentic dissection after successful coronars halloon angioplasiy: no influence on restenosis or on clinical outcome in 69,3 paticuls. J Am Coll Cardiol 1992:20:767-780.

8. Herman, WRM. Rensing BJ. Strauss BH, Serruy, PW. Methodological problems related to quantitative assersment of \irtels. clastic recoil, and balloon-artery ratio. Calh Cardivasc Diagn 1992:25:174-185.

9. J Jodgoon JM. Reddy KC. Suneja R, Vair RN. I.casnefsky FJ, Shechan IIM.

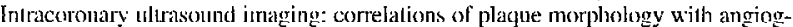
raphy, clinical syndrome and procedural results in patients undergoing coronary angioplastı. J Am Coll Cardiol 1993:21:35-44.

10. Fscaned J, Dorjol P, Di Mario C. Foley DP. Haase J, Baptista J. Mencvean N. den Boer A, L ighart I, Rocland JRTC. Serrus's PW. Does coronary lumen morphologs iniluence vessel cross-iectional area extiunation? An in villo comparison of intravascular ultrasound and quantialjic coronary angiography. In: Serruys PW, Ioley DP. de Fevter PJ. eds. Quantitative Coronary Angiography in Clinical Praclice. Dordrecht/New York. Ku1ler Acadeuic. 1994:681 693.

11. Haase J. Oraki K. Di Mario C. Fscaned J. de Fuyler P. Roeland JRTC. Selruys PW. (anl intracoromery ultrasound correctly alssess the luminal dimensions of coronary artery lesions? A comparison will quantiative angiography. Eur Ilear I 1994:16:112-119.

12. Polkin B.N. Keren G. Miuty G, Douck PC. Pichard AD, Satlur I F. Kent KY Leon MB. Arterial responses to balloon angioplasty: au intras ascular ultrasound siudy. I Am Coll Cardiol 1992:20:942-951.

13. Bloch PC. Myler RK. Sterter S. Iallon JT. Morphology atter transluminal angioplasy iut Jumun beings. N Engl J Mod 1981:305:382-385.

14. Waller BF. Farly and late mopplobogic changes in human coronary anteries atler percuraneons transluminal corolary augioplasty, Clin Cardiol 1983:6:363-372.

15. Kohcli K. Takebayashi S. Block PC. Hiroki T. Nouyushi M. Arterial changes atter percutaneous transhuminal coronetry angioplasty: results at autops: I Im Coll
Cardiol 1987:10:592 599.

16. Waller BF, "Crackers. breakers. stretchers. drillers, scrapers, shavers, bunlers welders and melters". - the tulure treament of atherosclerotic coronary artery disease? A clinical-morphologic arsessment. I Am Coll Cordiol 1989:13:969-987.

17. Mint/ (iS. Pichard AD. Kowach JA, Kent KM. Saller l fi. Javier SP. Popma JJ, Leon MB. Inpact of preinter'ention intravascular ultrasound innging on tranweatheter treatment strategics in coronury artery disease. $A m /$ Cardiof 1904 ; $74: 423-4: 30$.

18. Mater FA. Mint Gis. Pinnow E. Javier SP. Popma JJ. Kent KM, Satler L.t, Pichard AD, Leon MB. Multicariate prediclors of inlratascular ultrasound end points alser directional atherectomy. J Am Coll Cardiol 1995:25:318 324.

19. Ge J. Frbel R. Zamurano J. Koch L. Kearney P. Gorge (i. Gerber T. Veyer J. Coronary arter remodeling in alheroselerolje disease: an intravascular ultrasonic studs in vivo. Coron , Irtery Dis 1993:4:981 986.

20. The GUIDL 'lrial Investigators. IVLS-determined predictors of restenosis in PI'CA and I)CA: an interim report from the (II IDE trial. phase II (abstr). Circulation 1994:90(supp] I):[-23.

21. Jarb A. Virmani R. Atkinson JB. Koloxdgie FD, Plaque morphology and pathologic changes in arlerie, from patients dying affier coromary balloon angioplasts. I iln Coll Cardiol 1990:16:1+21-1429.

22. Losordo DW', Rosentield K. Piececk $\lambda$. Baker K. I larding M. Isner JM. How does angioplasty work? Serial analy'sjs of human iliac arteries using intravascular ultrisound. Circtataion 1992:80:1845 1858

23. Suneja R. Nair NR. Reckly KG, Rasheed Q. Sheclua TLM. I lodgson JM. Mechanisms of angiographically successful directional coronary atherectomy. Am IIear f 1993:126:507-514.

24. Braden GiA. Ilerrington DN. Downes TR. Kutcher MA, I itule WC. Qualitative and quantitalive contrasts in the mechanisms of lumson enlargemunt by corowary ballow angioplasis and directional coronary atherectomy. I Am Coll Cordiol (904:23:40 48

25. Baptisia J. Unans V.1. di .Mario C. Liscaned J. de Feyter PJ. Senuy PW. Mechanisms of luminal enlargement and quantification of vessel wall trauma follow ing balloon coronary angioplisty and directional atherettomy. A study using intracoronary nltrasound. arpioscopy and angiography. Eur Ilocar $J$ (in pross).

26. Honye J. Wahon IDJ, Jain $\Lambda$. White C. Ramee SR. Wallis JB. AI.-7arka A

Tobis JM. Morphologic eflects ol coronary balkon angioplasty in vivo assessed by inuravascular ultrasound injuing. Circhiation 1992:85:1012-1025.

27. Ro7cmman K, Gilon J), Welber S. Sapornikov D, Gotsman MS. Clinical and angionraphic prediclors of inmediate recoil af ter successtul coronary angioplasty and relation to latte restenosis. A $m$ J Cardiol 199.3:72:1020-1025.

28. I c R'I. J ore IIXI. Chung CiC. Lieberman LH. Jaramillo N. Schoen FJ. Computational ctructural analysis based on intravascular ultrasound imaging before in ritro angioplastl: prediction of plaque tracure locations. I Am Coll Cardiol 1993: 21:777-782

29. Pothin BN. Keren G. Mint G. Jonek PC. Pichard AD. Satler LF. Kent HKM. Leon MB. Arterial reyponses to balloon angioplasts: an intravascular ultrasound sudy. J ilm Coll Cardiol 1992:20:942 951.

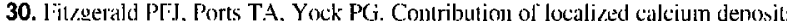
to dissection after angrioplasts. An observ ational study using intravelscular ultrsound. Cirrulation 1992:86:(64 70 . 